\title{
Effect of Different lodine Concentrations on Patient-Reported Discomfort in Contrast-Enhanced Computed Tomography: A Prospective Comparative Trial
}

\section{Effekt verschiedener Jodkonzentrationen auf patientenberichtete Missempfindungen während kontrastmittelverstärkter Computertomografie: Eine prospektive Vergleichsstudie}

Authors

Janis Lucas Vahldiek ${ }^{1}$, Lars-Arne Schaafs' ${ }^{1}$ Birgit K. Niehues², Bernd Hamm¹, Stefan Markus Niehues ${ }^{1}$

Affiliations

1 Department of Radiology, Charité-Universitätsmedizin Berlin, Germany

2 Rheumatology, Rheumazentrum Ruhrgebiet, Herne, Germany

Key words

adults, contrast media, iodine, computed tomography, high-concentration contrast media

received 09.05.2019

accepted 21.02.2020

\section{Bibliography}

DOI https://doi.org/10.1055/a-1132-5544

Published online: 26.3 .2020

Fortschr Röntgenstr 2020; 192: 945-951

(c) Georg Thieme Verlag KG, Stuttgart · New York

ISSN 1438-9029

Correspondence

Dr. Janis Lucas Vahldiek

Klinik für Radiologie, Charité-Universitätsmedizin Berlin,

Hindenburgdamm 30, 12203 Berlin, Germany

Tel.: ++49/30/84453041

janis.vahldiek@charite.de

\section{ZUSAMMENFASSUNG}

Ziele Die Reduktion der Injektionsgeschwindigkeit von jodhaltigen Kontrastmitteln kann kontrastmittelassoziierte Missempfindungen während CT-Untersuchungen reduzieren. Um eine exzellente Kontrastierung der Bilder zu garantieren, erfordert dieser Ansatz höher konzentrierte Kontrastmittel. Ob hochkonzentrierte Kontrastmittel die Patientenwahrnehmung während der CT-Untersuchung beeinflussen, ist bislang unzureichend untersucht. Das Ziel der vorliegenden Studie war es zu untersuchen, ob verschiedene Konzentrationen von intravenös verabreichtem, jodhaltigem Kontrastmittel einen Einfluss auf patientenberichtete Missempfindungen während der Untersuchung haben.
Material und Methoden Patienten wurde in 2 Gruppen randomisiert und erhielten entweder lomeprol $400 \mathrm{mg} / \mathrm{ml}$ (Gruppe A) oder lomeprol 300 mg/ml (Gruppe B) während Routine-CT-Untersuchungen. Jodinjektionsrate und Injektionszeit waren in beiden Gruppen gleich. Nach der kontrastmittelgestützten CT-Untersuchung beantworteten die Studienpatienten Fragen zu verschiedenen kontrastmittelassoziierten Missempfindungen mittels digitalen, visuellen Analogskalen (VAS).

Ergebnisse Innerhalb von 6 Monaten konnten 253 konsekutive Patienten eingeschlossen werden. In beiden Studiengruppen berichtete die Mehrheit der Patienten Wärme-Missempfindungen (Mittelwert VAS: 5,3 mm bei Gruppe A vs. 5,0 mm bei Gruppe $B ; p=0,5)$. Geschmackssensationen traten ebenso ohne signifikanten Unterschied in beiden Gruppen auf $(2,4 \mathrm{~mm}$ vs. 2,0 mm; $\mathrm{p}=0,08)$. Schmerzempfindungen traten signifikant geringer bei Studiengruppe B auf (1,3 mm vs. 1,0 mm; p = 0,005), obwohl Schmerzen während der Injektion bei beiden Studiengruppen auf sehr geringem Niveau berichtet wurden. Andere kontrastmittelassoziierte Missempfindungen wurden sehr selten angegeben.

Schlussfolgerungen Patientenberichtete Missempfindungen waren in beiden Studiengruppen (lomeprol $400 \mathrm{mg} / \mathrm{ml}$ vs. $300 \mathrm{mg} / \mathrm{ml}$ ) auf einem sehr geringen Niveau und unterschieden sich nur geringfügig zwischen beiden Studiengruppen. Die Injektion von höherkonzentriertem Kontrastmittel zeigte eine vergleichbare Patientenakzeptanz, was eine Reduktion der Injektionsgeschwindigkeit und des Injektionsvolumens während CT-Untersuchungen erlaubt.

\section{Kernaussagen:}

- Patientenberichtete Missempfindungen waren in dieser Studie auf einem sehr geringen Niveau.

- Das höherkonzentrierte Kontrastmittel (HKKM) zeigte im Vergleich eine analog hohe Patientenakzeptanz.

- HKKM erlauben geringere Injektionsraten bei gleichbleibender Jod-Flussrate. 


\section{ABSTRACT}

Purpose Reducing contrast media injection speed while maintaining iodine flux is a promising workaround to lower or avoid contrast media-related discomfort during CT examinations. This approach demands contrast media with a higher concentration to guarantee excellent image quality. It remains unclear whether these concentration changes affect the patient's experience. Thus, the aim of this study was to evaluate the influence of different concentrations of intravenous iodinated contrast media on patient discomfort during and after contrast media delivery.

Materials and Methods Patients were randomized to receive either lomeprol $400 \mathrm{mg} / \mathrm{ml}$ (group A) or $300 \mathrm{mg} / \mathrm{ml}$ (group B) during routinely scheduled CT examinations at our department. The iodine delivery rate and injection time were kept constant in both groups. After examination, study subjects completed a digital questionnaire on different CM-related sensation items using digital visual analogue scales.

Results 253 consecutive patients were enrolled in a 6-month period. Most of the patients reported heat sensation in both groups (mean VAS: $5.3 \mathrm{~mm}$ in group A vs. $5.0 \mathrm{~mm}$ in group $B$, $\mathrm{p}=0.5)$. Taste sensation also did not differ significantly between both groups ( $2.4 \mathrm{~mm}$ vs. $2.0 \mathrm{~mm}, \mathrm{p}=0.08$ ). Pain sensation was reported to be significantly lower in group $B$ patients $(1.3 \mathrm{~mm}$ vs. $1.0 \mathrm{~mm}, \mathrm{p}=0.005)$, even though pain sensation in general was reported on a very low level. Other injection-related sensations were rarely reported.

Conclusion Patient-reported discomfort during intravenous injection of high-concentration contrast media $(400 \mathrm{mg} / \mathrm{ml})$ was low and only marginally different when compared to the injection of contrast media with a lower concentration. The injection of highly concentrated contrast media showed comparable overall patient acceptance, allowing a reduction of the injection speed and volume during examinations.

\section{Key Points:}

- Patient-reported, contrast-related discomfort was very low in this study.

- High-concentration contrast media (HCCM) showed comparable overall patient acceptance.

- HCCM allow a reduction of injection speeds while keeping iodine flux constant.

\section{Citation Format}

- Vahldiek JL, Schaafs LA, Niehues BK et al. Effect of Different lodine Concentrations on Patient-Reported Discomfort in Contrast-Enhanced Computed Tomography: A Prospective Comparative Trial. Fortschr Röntgenstr 2020; 192: 945951

\section{Introduction}

The introduction of computed tomography (CT) in the $1970 \mathrm{~s}$ has led to epochal achievements in medical imaging. Nowadays, it is a day-to-day tool for the noninvasive diagnosis of numerous diseases. Reliable CT depends greatly on the use of intravenous, iodinated contrast media (CM). Different types of iodinated CM are available. High to low concentrations of iodine allow the injection of different CM volumes [1].

CM injection-related discomfort and adverse reactions (ADR) have been a well-known problem since the $1980 \mathrm{~s}$ but have decreased [2-4]. Modern non-ionic contrast media are reported to be safe [1]. Besides adverse effects, CM injection is often accompanied by patient discomfort including heat, taste and pain sensations [5-7]. A cold sensation, nausea, pruritus and the desire to urinate are rarely reported. Risk factors and significance of these CM-related sensations remain unclear [8]. Adverse reactions and sensations may be correlated with the iodine concentration of the $\mathrm{CM}$, the injected volume, the injection rate or the site of the injection [9-13].

Reducing the CM injection speed is suggested as a promising workaround to lower or avoid CM-related discomfort during CT examinations [14]. In order to guarantee excellent image quality, this approach demands a high iodine concentration of the CM to keep the iodine flux (delivered iodine amount per time, iodine flux $\mathrm{F}[\mathrm{mg} / \mathrm{s}]=\mathrm{c}_{0}[\mathrm{mg}$ iodine $\left./ \mathrm{ml}]{ }^{*} \mathrm{v}[\mathrm{ml} / \mathrm{s}]\right)$ constant.

The purpose of the current study was to evaluate the influence of different concentrations of intravenous CM on patient-reported discomfort during and after CM delivery.

\section{Materials and Methods}

\section{Study Design}

The study was designed as a single-center pilot study. It was a prospective, observational, non-interventional, comparative trial that was conducted at a maximum-care hospital in Germany. The trial was conducted in full conformance with the Declaration of Helsinki and was approved by our institutional review board/local ethics committee. All patients gave informed consent.

During the study period, all patients in our department that were scheduled for diagnostic, routine contrast-enhanced computed tomography (CECT) were asked to participate in this study. Upon consent, patients answered a dedicated digital questionnaire immediately after their examination in order to assess contrast media-related sensations and discomfort.

To evaluate the influence of different concentrations of intravenous contrast media (CM) on patient discomfort during and after CM delivery, participating patients were randomized into two groups. During the first study period, all consecutive patients were examined using lomeprol $400 \mathrm{mg} / \mathrm{ml}$ intravenously (group A). Thereafter, all consecutive patients received Iomeprol $300 \mathrm{mg} / \mathrm{ml}$ during CECT (group B) [both: Imeron ${ }^{\circledR}$, Bracco Imaging Deutschland $\mathrm{GmbH}$, Germany]. This approach ensured a certain level of randomization of patients. In both study groups, standardized CM injection protocols were chosen based on indication and referral diagnosis (i. e., tumor screening, tumor staging, aortic aneurysm). While keeping contrast timing, iodine flux and overall iodine amount constant in both study groups, the use of 
- Table 1 Two exemplary contrast media injection protocols used in this study.

- Tab.1 Zwei exemplarische, in dieser Studie verwendete Kontrastmittel-Injektionsprotokolle.

\begin{tabular}{|c|c|c|}
\hline $\begin{array}{l}\text { contrast media } \\
\text { protocol }\end{array}$ & $\begin{array}{l}\text { lomeprol } 400 \mathrm{mg} / \mathrm{ml} \\
\text { (group A) }\end{array}$ & $\begin{array}{l}\text { lomeprol } 300 \mathrm{mg} / \mathrm{ml} \\
\text { (group B) }\end{array}$ \\
\hline \multicolumn{3}{|l|}{ aortic aneurysm } \\
\hline $\begin{array}{l}\text { - injection } \\
\text { speed }\end{array}$ & $4.0 \mathrm{ml} / \mathrm{s}$ & $5.3 \mathrm{ml} / \mathrm{s}$ \\
\hline $\begin{array}{l}\text { - injected } \\
\text { volume }\end{array}$ & $100 \mathrm{ml}$ & $133 \mathrm{ml}$ \\
\hline - iodine flux & $1600 \mathrm{mg} / \mathrm{s}$ & $1590 \mathrm{mg} / \mathrm{s}$ \\
\hline - iodine amount & $40000 \mathrm{mg}$ & $39900 \mathrm{mg}$ \\
\hline - injection time & $25.0 \mathrm{~s}$ & $25.1 \mathrm{~s}$ \\
\hline \multicolumn{3}{|l|}{ tumor staging } \\
\hline $\begin{array}{l}\text { - injection } \\
\text { speed }\end{array}$ & $2.5 \mathrm{ml} / \mathrm{s}$ & $3.3 \mathrm{ml} / \mathrm{s}$ \\
\hline $\begin{array}{l}\text { - injected } \\
\text { volume }\end{array}$ & $100 \mathrm{ml}$ & $133 \mathrm{ml}$ \\
\hline - iodine flux & $1000 \mathrm{mg} / \mathrm{s}$ & $990 \mathrm{mg} / \mathrm{s}$ \\
\hline - iodine amount & $40000 \mathrm{mg}$ & $39900 \mathrm{mg}$ \\
\hline - injection time & $40.0 \mathrm{~s}$ & $40.0 \mathrm{~s}$ \\
\hline
\end{tabular}

differently iodinated CM $(300 \mathrm{mg} / \mathrm{ml}$ vs. $400 \mathrm{mg} / \mathrm{ml})$ enabled us to vary the injection flow and injected volume between the two groups. This resulted in a group with relatively low injection speeds (group A) compared to the higher injection speeds applied in group B subjects with constant iodine flux in both groups.

- Table 1 shows different exemplary injection protocols for both study groups. Every study subject was examined in the same examination room with the same 80-slice MDCT scanner (Aquilion PRIME, Canon Medical Systems, Otawara, Japan). Intravenous CM injection was performed via a 20 -gauge venous access system using an Accutron CT-D injection system (Medtron AG, Germany) followed by a bolus of $40 \mathrm{ml}$ of saline as a chaser.

\section{Digital Questionnaire}

We developed a dedicated questionnaire application using Xcode 6.3 build $6 \mathrm{D} 570$ and iOS software development kit 8.3 build 12F69 (Apple Inc., 1 Infinite Loop, Cupertino, CA 95 014, USA). The application was installed on two tablet computers (iPad Air2, iOS 8.3, Apple Inc.) that were wall-mounted in the CT waiting areas. Study patients were able to initiate a new questionnaire by scanning their personal QR code with the device's internal camera. The dedicated application guided patients through 8 digital sheets with a total of 12 questions. The data entered by the patient was encrypted and stored in a local database on the device. After study completion, all patient-generated data was exported to a CSV file and imported into SPSS (IBM Corp., Version 22.0., USA).
Since there are no standardized and validated assessment tools for measuring patient experience during CM injection, we developed our own questionnaire. To ensure correct study design, independent psychologists approved the validity of the dedicated questionnaire used in this study.

Immediately after CECT acquisition was completed, every study subject was asked to answer the digital questionnaire about CM-related discomfort using one of the iPads. This approach was intended to ensure high participation rates and good reliability as well as high completion rates. Data acquisition was completely anonymized. Therefore, all patients received a personal study ID encoded in a printed QR code. Medical technical assistants recorded patient-specific CM injection parameters on a dedicated paper card on which the corresponding study ID was also printed encoded in a QR code for subsequent data entry of injection details. Discomfort and sensations were recorded using a digital visual analogue scale (VAS) of $100 \mathrm{~mm}$. All VAS-assessed questionnaire items are specified in $\boldsymbol{\nabla}$ Table $\mathbf{2}$.

\section{Analysis}

SPSS was used for data analysis (IBM Corp.). Descriptive statistical analysis included the calculation of absolute and relative frequencies, mean values and corresponding standard deviations (SD). Group differences were identified by applying the student's t-test for parametric data or applying the Mann-Whitney test for ordinal data. The difference in frequencies between the study groups was analyzed by applying the Fisher's exact test. The significance level was set to 0.05 or less.

\section{Results}

We tested the patient's subjective discomfort in relation to different concentrations of intravenous CM during routine computed tomography examinations in 253 consecutive patients. All patients completed the digital questionnaire immediately after their examination. 128 patients received lomeprol with a concentration of $400 \mathrm{mg} / \mathrm{ml}$ (group A, lower injection speeds), 125 patients lomeprol with a concentration of $300 \mathrm{mg} / \mathrm{ml}$ (group B, higher injection speeds).

- Table 3 shows the baseline characteristics and demographic data. - Table 4 summarizes the CM injection parameters for both study groups. As intended by study design, the flow rate and injected volume differed significantly between both study arms. As expected, no significant differences in iodine flux, delivered iodine amount and injection time were observed.

\section{Contrast Media-Related Sensations}

In general, all of the study subjects tolerated the CM injection well in both study groups. Heat sensation was the most frequently reported sensation ( $N=244,96.4 \%$ of cases), followed by taste $(\mathrm{N}=177,70.0 \%)$ and pain sensation $(\mathrm{N}=140,55.3 \%)$. T Table 5 summarizes the VAS-assessed discomfort and sensation questions for the whole study population. No contrast media extravasation occurred in all patients. An absence of pain sensation 
- Table 2 Detailed specifications of the VAS-assessed questionnaire items used in this study.

- Tab.2 Detaillierte Beschreibung der mittels visueller Analogskala erhobenen Fragen dieser Studie.

\begin{tabular}{|c|c|c|c|c|}
\hline questionnaire item & short descriptor & type & label at $0 \mathrm{~mm}$ & label at $100 \mathrm{~mm}$ \\
\hline how would you describe the contrast injection? & general experience & mandatory & $\begin{array}{l}\text { completely } \\
\text { unproblematic }\end{array}$ & $\begin{array}{l}\text { extremely } \\
\text { uncomfortable }\end{array}$ \\
\hline $\begin{array}{l}\text { to what extent did you experience a feeling of } \\
\text { warmth during contrast injection? }\end{array}$ & heat sensation & mandatory & no heat sensation & $\begin{array}{l}\text { extremely strong } \\
\text { heat sensation }\end{array}$ \\
\hline $\begin{array}{l}\text { to what extent did you experience an unpleasant } \\
\text { taste during contrast injection? }\end{array}$ & taste sensation & mandatory & no unpleasant taste & extremely bad taste \\
\hline how much pain did you feel during the injection? & pain sensation & mandatory & no pain & extreme pain \\
\hline $\begin{array}{l}\text { to what extent did you feel a cold sensation } \\
\text { during contrast injection? }\end{array}$ & cold sensation & optional & very slight & extreme \\
\hline $\begin{array}{l}\text { how much nausea did you feel during the } \\
\text { injection? }\end{array}$ & nausea & optional & very slight & extreme \\
\hline $\begin{array}{l}\text { how much itching did you feel during the } \\
\text { injection? }\end{array}$ & pruritus & optional & very slight & extreme \\
\hline $\begin{array}{l}\text { how much urinary urgency did you feel during } \\
\text { the injection? }\end{array}$ & $\begin{array}{l}\text { feeling of the } \\
\text { need to urinate }\end{array}$ & optional & very slight & extreme \\
\hline $\begin{array}{l}\text { what is your attitude towards future } \\
\text { CT examinations with CM injection? }\end{array}$ & - & mandatory & $\begin{array}{l}\text { was okay, I would } \\
\text { undergo again }\end{array}$ & $\begin{array}{l}\text { I would never } \\
\text { undergo again }\end{array}$ \\
\hline
\end{tabular}

- Table 3 Baseline characteristics and demographic data $(N=253)$.

- Tab. 3 Basischarakteristika und demografische Daten der Studie $(\mathrm{N}=253)$.

\begin{tabular}{|l|c|c|c|}
\hline & $\begin{array}{l}\text { lomeprol } \\
\mathbf{4 0 0} \mathbf{~ m g / m l}\end{array}$ & $\begin{array}{l}\text { lomeprol } \\
\mathbf{3 0 0} \mathbf{~ m g / m l}\end{array}$ & total \\
\hline $\begin{array}{l}\text { completed ques- } \\
\text { tionnaires (\%) }\end{array}$ & $125(\mathbf{4 9 . 4 )}$ & $128(50.6)$ & $253(100)$ \\
\hline $\begin{array}{l}\text { male gender (\%) } \\
\text { mean response time }\end{array}$ & $76(60.8)$ & $68(53.1)$ & $144(57)$ \\
\hline $\begin{array}{l}\text { in seconds (SD) } \\
\text { outpatients (\%) }\end{array}$ & $69(55.2)$ & $107(47)$ & $105(44)$ \\
\hline
\end{tabular}

during contrast delivery was reported statistically more frequently in group B patients (lomeprol $300 \mathrm{mg} / \mathrm{ml}$, > Table 6).

\section{Other Contrast Media-Related Sensations}

38 patients $(15.0 \%)$ reported other CM-related sensations, 20 subjects of group A (lomeprol $400 \mathrm{mg} / \mathrm{ml}$ ) and 18 of group B (lomeprol $300 \mathrm{mg} / \mathrm{ml}$ ). In these subgroups, the feeling of the need to urinate was the most frequently mentioned sensation $(N=12$ in group $A$ vs. $N=18$ in group $B$ ). Cold sensation ( $N=6$ vs. $N=2$ ), nausea ( $N=5$ vs. $\mathrm{N}=2$ ) and pruritus ( $N=0$ vs. $N=1$ ) were less frequently mentioned sensations. - Table 7 summarizes the quantification of these other reported sensations assessed by VAS.
- Table 4 Mean (standard deviation) of contrast media injection parameters for the lower flow group (lomeprol $400 \mathrm{mg} / \mathrm{ml}, \mathrm{N}=125$ ) and the higher flow group (lomeprol $300 \mathrm{mg} / \mathrm{ml}, \mathrm{N}=128$ ).

- Tab.4 Mittelwerte und Standardabweichungen der verwendeten Kontrastmittel-Injektionsparameter getrennt nach Studiengruppen $(N=253)$.

\begin{tabular}{|l|l|l|l|}
\hline & $\begin{array}{l}\text { lomeprol } \\
\mathbf{4 0 0} \mathbf{~} \mathbf{g} / \mathbf{m l}\end{array}$ & $\begin{array}{l}\text { lomeprol } \\
\mathbf{3 0 0} \mathbf{~ m g / m l}\end{array}$ & p-value \\
\hline flow rate $\mathrm{ml} / \mathrm{s}$ & $3.0(0.7)$ & $4.0(0.9)$ & $<0.001^{2}$ \\
\hline volume ml & $88.4(17.0)$ & $116.6(22.4)$ & $<0.001^{2}$ \\
\hline iodine amount mg & $35360(6785)$ & $34978(6729)$ & 0.65 \\
\hline injection time s & $31.1(9.3)$ & $30.5(8.1)$ & 0.59 \\
\hline iodine flux mg/s & $1201.6(276.5)$ & $1192.5(261.8)$ & 0.78 \\
\hline $\begin{array}{l}\text { 1 Student's t-test. } \\
\text { t-Test. } \\
\text { statistically significant. } \\
\text { statistisch signifikant. }\end{array}$ & & \\
\hline
\end{tabular}

\section{Attitude Towards Future CM Injections}

The last question asked the study patients about their opinion towards future CECT examinations. The average VAS values for this question were very low in both study groups, although a large variation was evident in the whole study population. The mean $( \pm S D)$ VAS value was $1.2( \pm 1.5)$ in group A patients (lomeprol $400 \mathrm{mg} / \mathrm{ml}$ ) and $0.8( \pm 1.3)$ in the group B subjects (lomeprol 
- Table 5 Mean values of general experience, heat, pain and taste sensations evaluated by visual analogue scale in both study arms ( $\mathrm{N}=253$ ).

- Tab.5 Mittelwerte der mittels visueller Analogskala erfassten Endpunkte generelle Erfahrung, Wärme-, Schmerz- und Geschmacks-Missempfindungen in beiden Studiengruppen ( $\mathrm{N}=253)$.

\begin{tabular}{|c|c|c|c|c|c|}
\hline VAS & study arm & $\mathbf{n}$ & mean $(\mathrm{mm})$ & $\mathrm{SD}(\mathrm{mm})$ & p-value ${ }^{1}$ \\
\hline general experience & $\begin{array}{l}\text { lomeprol } 400 \\
\text { lomeprol } 300\end{array}$ & $\begin{array}{l}125 \\
128\end{array}$ & $\begin{array}{l}2.1 \\
1.6\end{array}$ & $\begin{array}{l}2.0 \\
2.1\end{array}$ & $0.003^{2}$ \\
\hline heat sensation & $\begin{array}{l}\text { lomeprol } 400 \\
\text { lomeprol } 300\end{array}$ & $\begin{array}{l}125 \\
128\end{array}$ & $\begin{array}{l}5.3 \\
5.0\end{array}$ & $\begin{array}{l}2.3 \\
2.8\end{array}$ & 0.495 \\
\hline pain sensation & $\begin{array}{l}\text { lomeprol } 400 \\
\text { lomeprol } 300\end{array}$ & $\begin{array}{l}125 \\
128\end{array}$ & $\begin{array}{l}1.3 \\
1.0\end{array}$ & $\begin{array}{l}1.6 \\
2.0\end{array}$ & $0.005^{2}$ \\
\hline taste sensation & $\begin{array}{l}\text { lomeprol } 400 \\
\text { lomeprol } 300\end{array}$ & $\begin{array}{l}125 \\
128\end{array}$ & $\begin{array}{l}2.4 \\
2.0\end{array}$ & $\begin{array}{l}2.6 \\
2.5\end{array}$ & 0.079 \\
\hline $\begin{array}{l}1 \text { Mann-Whitney test. } \\
\text { Mann-Whitney-Test. } \\
2 \text { statistically significant. } \\
\text { statistisch signifikant. }\end{array}$ & & & & & \\
\hline
\end{tabular}

- Table 6 Absence of CM-related sensations of heat, pain and taste in both study groups $(\mathrm{N}=253)$.

- Tab. 6 Fehlen von den Kontrastmittel-assoziierten Missempfindungen Wärmegefühl, Schmerz und Geschmackssensation in beiden Studiengruppen $(\mathrm{N}=253)$.

\begin{tabular}{|c|c|c|c|c|}
\hline & arm & n & $\%$ & p-value ${ }^{1}$ \\
\hline $\begin{array}{l}\text { no heat } \\
\text { sensation }\end{array}$ & $\begin{array}{l}\text { lomeprol } 400 \\
\text { lomeprol } 300\end{array}$ & $\begin{array}{l}2 / 125 \\
7 / 128\end{array}$ & $\begin{array}{l}1.6 \\
5.5\end{array}$ & 0.172 \\
\hline $\begin{array}{l}\text { no pain } \\
\text { sensation }\end{array}$ & $\begin{array}{l}\text { lomeprol } 400 \\
\text { lomeprol } 300\end{array}$ & $\begin{array}{l}44 / 125 \\
69 / 128\end{array}$ & $\begin{array}{l}35.2 \\
53.9\end{array}$ & 0.004 \\
\hline $\begin{array}{l}\text { no taste } \\
\text { sensation }\end{array}$ & $\begin{array}{l}\text { lomeprol } 400 \\
\text { Iomeprol } 300\end{array}$ & $\begin{array}{l}32 / 125 \\
44 / 128\end{array}$ & $\begin{array}{l}25.6 \\
34.4\end{array}$ & 0.134 \\
\hline
\end{tabular}

$300 \mathrm{mg} / \mathrm{ml}$ ). This slight difference between both study groups was not statistically significant $(p=0.057)$.

\section{Discussion}

The presented pilot study provides an analysis of the patient's subjective experience during standardized CT contrast administration at different iodine levels of 300 and $400 \mathrm{mg} / \mathrm{ml}$ while keeping the iodine delivery rate and injection time constant in both study groups. This enabled us to significantly reduce the injection rate in the $400 \mathrm{mg} / \mathrm{ml}$ study group.

While many studies focus on acute and late adverse reactions [15-17], this study evaluates the patient's experience as the main item of acceptance. We observed only minor differences in the
- Table 7 Mean values of urinary urgency, cold sensation, nausea and pruritus evaluated by visual analogue scale in both study arms.

- Tab. 7 Mittelwerte der mittels visueller Analogskala erfassten Missempfindungen Gefühl des Einnässens, Kälte, Übelkeit und Juckreiz in beiden Studiengruppen.

\begin{tabular}{|l|l|l|l|l|}
\hline VAS & arm & $\mathbf{n}$ & $\begin{array}{l}\text { mean } \\
\mathbf{( m m )}\end{array}$ & $\begin{array}{l}\text { SD } \\
\mathbf{( m m}\end{array}$ \\
\hline \multirow{2}{*}{ urinary urgency } & $\begin{array}{l}\text { lomeprol 400 } \\
\text { lomeprol 300 }\end{array}$ & 18 & 5.1 & 2.5 \\
\hline cold sensation & lomeprol 400 & 6 & 5.0 & 3.6 \\
\hline \multirow{2}{*}{ nausea } & lomeprol 300 & 2 & 3.5 & 0.5 \\
\hline pruritus & lomeprol 400 & 5 & 6.5 & 1.9 \\
\hline & lomeprol 300 & 2 & 3.6 & 5.1 \\
\hline & lomeprol 400 & 1 & 6.0 & - \\
\hline & lomeprol 300 & 0 & - & - \\
\hline
\end{tabular}

patient-reported, contrast-injection-related sensations of heat, taste and pain between both of our study groups $(300 \mathrm{mg} / \mathrm{ml}$ vs. $400 \mathrm{mg} / \mathrm{ml}$ ). All of these reported sensations were always slightly lower in the $300 \mathrm{mg} / \mathrm{ml}$ group. Heat and taste sensation did not differ significantly between the two groups. The reported pain sensation during contrast delivery was significantly lower in the $300 \mathrm{mg} / \mathrm{ml}$ group, although the difference in absolute values was only minor (mean VAS value 1.0 vs. 1.3) and on a very low level. Furthermore, the proportion of patients that reported no pain sensation at all was significantly lower in the $300 \mathrm{mg} / \mathrm{ml}$ group ( $35.2 \%$ vs. $53.9 \%$ ). These pain-related group distinctions probably accounted for a significantly better general perception of contrast injection in the $300 \mathrm{mg} / \mathrm{ml}$ study group, even though the difference in the mean VAS values was only moderate (1.6 vs. 2.1). We observed a slight but not statistically significant difference when 
asking patients about their attitude to repeat computed tomography with contrast administration. This slight difference in favor of the lower concentrated contrast agent might indicate a certain trend if evaluated in a larger population. Nevertheless, this difference was on a very low level indicating the overall high acceptance of contrast injection.

We did not encounter any moderate or severe adverse drug reactions (ADR) as defined in the ESUR guidelines [18]. Although warmth is defined as a mild chemotoxic acute reaction, the recent publications in this field excluded heat/warmth sensations from ADR $[14,19]$. In our study, the majority of patients (96.4\%) reported a feeling of heat as the main sensation, which is in accordance with other prior studies [20]. In line with previous studies, other injection-related sensations were rarely reported in our study [5, 7].

We used a dedicated digital questionnaire presented on tablet computers for data collection. Most of our study subjects appreciated this approach. Patient-reported digital data assessments offer several benefits since acquisition is fast, convenient, reliable and can help reduce the problem of missing data [21, 22]. A recent meta-analysis proved that paper-based and electronic assessment tools are equivalent with regard to measuring patient-reported data [23].

This study has some limitations. First, the en bloc recruitment and randomization of patients to both study groups could be a substantial selection bias since several studies have shown seasonal dependency of contrast-related sensations [24]. Informed consent may represent another bias of this study since study subjects were educated about possibly occurring sensations prior to their examination. Thus, the reported VAS values for the assessed sensations may be overestimated because study patients were aware of possible sensations that they might have not recognized without prior education. Furthermore, some of the elderly patients needed help using the electronic questionnaire. These cases received technical assistance, which might have influenced the precision of the values on the digital VAS. As both study groups received this kind of assistance, this possible bias might have affected both groups to the same extent.

Another limitation is the relatively small sample size of 253 cases which may limit the power to draw conclusions regarding the investigated endpoints. Age and gender probably significantly influence patient-reported, contrast agent-related discomfort [20]. Unfortunately, we were not able to perform matching of patients for these parameters from our data. Future studies on patient-reported discomfort should include a matched pairs analysis for both parameters in order to obtain more reliable results on group differences. Furthermore, we adjusted injection speed and injection volume to keep the iodine flux and amount constant between both study groups. This might have biased our results since injection speed as well as injection volume both are known to have an influence on patient-related discomfort during contrast media injection [9-12].

In conclusion, patient-reported discomfort during the intravenous injection of highly concentrated contrast media $(400 \mathrm{mg} / \mathrm{ml})$ was low in this pilot study and was only marginally different compared with the injection of lower-concentration contrast media $(300 \mathrm{mg} / \mathrm{ml})$ when adapting the application rate and injection vol- ume. The injection of highly concentrated contrast media showed high patient acceptance allowing a significant reduction of the CM injection flow and volume without affecting contrast behavior.

\section{CLINICAL RELEVANCE OF THIS STUDY}

- Slower injection rates of iodinated contrast media could reduce contrast media-related discomfort during CT examinations.

- Highly concentrated contrast agents allow for a reduction of injection speed and injection volume and guarantee constantly high image quality.

- The injection of high-concentration contrast media showed high overall patient acceptance in this study.

\section{Conflict of Interest}

\section{J.L. Vahldiek: grants from Merit Medical}

L.A. Schaafs: nothing to disclose

B.K. Niehues nothing to disclose

B. Hamm: grants from Abbott, grants from Actelion Pharmaceuticals, grants from Bayer Schering Pharma, grants from Bayer Vital, grants from BRACCO Group, grants from Bristol-Myers Squibb, grants from Charité research organisation $\mathrm{GmbH}$, grants from Deutsche Krebshilfe, grants from Dt. Stiftung für Herzforschung, grants from Essex Pharma, grants from EU Programmes, grants from Fibrex Medical Inc., grants from Focused Ultrasound Sugery Foundation, grants from Fraunhofer Gesellschaft, grants from Guerbet, grants from INC Research, grants from InSightec Ltd., grants from IPSEN Pharma, grants from Kendle/MorphoSys AG, grants from Lilly $\mathrm{GmbH}$, grants from Lundbeck $\mathrm{GmbH}$, grants from MeVis Medical Solutions AG, grants from Nexus Oncology, grants from Novartis, grants from Parexel CRO Service, grants from Perceptive, grants from Pfizer $\mathrm{GmbH}$, grants from Philipps, grants from sanofisaventis S.A., grants from Siemens, grants from Spectranetics $\mathrm{GmbH}$, grants from Terumo Medical Corporation, grants from TNS Healthcare $\mathrm{GmbH}$, grants from Toshiba, grants from UCB Pharma, grants from Wyeth Pharma, grants from Zukunftsfond Berlin (TSB)

S.M. Niehues: grants from Canon Medical Systems, grants from Bayer Healthcare, grants from Guerbet, grants from Bracco, grants from Teleflex Medical GmbH

\section{References}

[1] Christiansen C. X-ray contrast media-an overview. Toxicology 2005; 209: 185-187

[2] Hagen B, Clauss W. Contrast media and pain in peripheral arteriography. Randomized, intra-individual double-blind trial: ioglicinate, ioglicinate-lidocaine, ioxaglate. Der Radiologe 1982; 22: 470-475

[3] Hagen B. lopamidol, a new non-ionic roentgen contrast medium. Results of angiographic studies in more than 300 patients, with special reference to pain reactions. Der Radiologe 1982; 22: 581-585

[4] Rose TA Jr, Choi JW. Intravenous Imaging Contrast Media Complications: The Basics That Every Clinician Needs to Know. The American journal of medicine 2015; 128: 943-949

[5] Wang H, Wang HS, Liu ZP. Agents that induce pseudo-allergic reaction. Drug discoveries \& therapeutics 2011; 5: 211-219

[6] Palkowitsch P, Lengsfeld $P$, Stauch $K$ et al. Safety and diagnostic image quality of iopromide: results of a large non-interventional observational study of European and Asian patients (IMAGE). Acta radiologica 2012; 53: 179-186 
[7] Palkowitsch PK, Bostelmann S, Lengsfeld P. Safety and tolerability of iopromide intravascular use: a pooled analysis of three non-interventional studies in 132012 patients. Acta radiologica 2014; 55: 707-714

[8] Palena LM, Sacco ZD, Brigato C et al. Discomfort assessment in peripheral angiography: randomized clinical trial of lodixanol 270 versus loversol 320 in diabetics with critical limb ischemia. Catheterization and cardiovascular interventions: official journal of the Society for Cardiac Angiography \& Interventions 2014; 84: 1019-1025

[9] Cochran ST, Bomyea K, Sayre JW. Trends in adverse events after IV administration of contrast media. Am J Roentgenol American journal of roentgenology 2001; 176: 1385-1388

[10] Jacobs JE, Birnbaum BA, Langlotz CP. Contrast media reactions and extravasation: relationship to intravenous injection rates. Radiology 1998; 209: 411-416

[11] Katayama H. Adverse reactions to contrast media. What are the risk factors? Investigative radiology 1990; 25 (Suppl. 1): S16-S17

[12] Katayama H, Yamaguchi K, Kozuka T et al. Adverse reactions to ionic and nonionic contrast media. A report from the Japanese Committee on the Safety of Contrast Media. Radiology 1990; 175: 621-628

[13] Mihl C, Maas M, Turek J et al. Contrast Media Administration in Coronary Computed Tomography Angiography - A Systematic Review. Röfo 2017; 189: 312-325

[14] Li X, Liu H, Zhao L et al. Clinical observation of adverse drug reactions to non-ionic iodinated contrast media in population with underlying diseases and risk factors. The British journal of radiology 2017; 90: 20160729

[15] Mikkonen R, Kontkanen T, Kivisaari L. Acute and late adverse reactions to low-osmolal contrast media. Acta radiologica 1995; 36: 72-76
[16] Muller FH. Post-marketing surveillance of the safety profile of iodixanol in the outpatient CT setting: a prospective, multicenter, observational study of patient risk factors, adverse reactions and preventive measures in 9953 patients. Röfo 2014; 186: 1028-1034

[17] Gomi T, Nagamoto M, Hasegawa $M$ et al. Are there any differences in acute adverse reactions among five low-osmolar non-ionic iodinated contrast media? Eur Radiol 2010; 20: 1631-1635

[18] van der Molen AJ, Reimer P, Dekkers IA et al. Post-contrast acute kidney injury - Part 1: Definition, clinical features, incidence, role of contrast medium and risk factors. Eur Radiol 2018; 28: 2845-2855

[19] Radiology ACo. ACR Manual on Contrast Media - Version 10.3 2017.

[20] McCullough PA, Capasso P. Patient discomfort associated with the use of intra-arterial iodinated contrast media: a meta-analysis of comparative randomized controlled trials. BMC Med Imaging 2011; 11: 12

[21] Deshpande PR, Rajan S, Sudeepthi BL et al. Patient-reported outcomes: A new era in clinical research. Perspectives in clinical research 2011; 2: 137-144

[22] Duracinsky M, Lalanne C, Goujard C et al. Electronic versus paper-based assessment of health-related quality of life specific to HIV disease: reliability study of the PROQOL-HIV questionnaire. Journal of medical Internet research 2014; 16: e115

[23] Gwaltney C], Shields AL, Shiffman S. Equivalence of electronic and paperand-pencil administration of patient-reported outcome measures: a meta-analytic review. Value in health: the journal of the International Society for Pharmacoeconomics and Outcomes Research 2008; 11 : 322-333

[24] Ho J, Kingston RJ, Young $\mathrm{N}$ et al. Immediate hypersensitivity reactions to IV non-ionic iodinated contrast in computed tomography. Asia Pacific allergy 2012; 2: 242-247 